\title{
New species and new combinations of Asian Batrisodes Reitter (Coleoptera, Staphylinidae, Pselaphinae), and synonymy of Batrisodellus Jeannel with Batrisodes
}

\author{
Zi-Wei Yin ${ }^{1}$, Jia-Wei Shen ${ }^{1}$, Li-Zhen Li $^{1}$ \\ 1 Department of Biology, College of Life and Environmental Sciences, Shanghai Normal University, Shanghai, 200234, P. R. China \\ http://zoobank.org/EA8D190E-0E7C-4E04-9E96-65EC0E75D6D1 \\ Corresponding author: Li-Zhen Li (lizhenli@shnu.edu.cn)
}

Received 18 January 2015

Accepted 12 February 2015

Published 17 March 2015

Academic editor:

Alexey Solodovnikov

\section{Key Words}

\section{Batrisodes}

new species

new combination

new synonymy

homonym

Russia

China

\begin{abstract}
Continuing surveys on the pselaphine fauna in China have revealed four undescribed species of the genus Batrisodes: Batrisodes angustelytratus sp. n. (with Pachycondyla ant) and B. longwangshanus sp. n. from Zhejiang, B. bamian sp. n. (with Pseudolasius ant) from Hunan, and $B$. songxiaobini sp. n. (with Formica ant) from Yunnan. The genus Batrisodellus is placed as a junior synonym of Batrisodes, syn. n.; this taxonomic act results in eight new combinations: Batrisodes cerberus, B. coprea, B. cristatus, B. fengtingae, B. laticollis, B. longulus, B. palpalis, and B. punctipennis. The Russian Far East species Basitrodes cornutus is transferred to Batrisodes, comb. $\mathbf{n}$.
\end{abstract}

\section{Introduction}

The fauna of the largely Holarctic genus Batrisodes Reitter in China is poorly explored. Currently only four species of this genus have been known: two from the mainland and two from Taiwan. Three of them, B. masatakai Nomura, B. babaianus Nomura, and B. simplex Yin \& $\mathrm{Li}$, are placed in the subgenus Excavodes Park (Nomura 2007, Yin and Li 2013), and one, B. pruinosus (Reitter), in the nominotypical subgenus (Besuchet 1981). Recent surveys on the pselaphine beetles in eastern, central, and southwestern China in 2013 and 2014 have revealed four undescribed Batrisodes species that are described herein. Of them, three were collected from colonies of the ant genera Pachycondyla Smith, Pseudolasius Emery, and Formica Linnaeus. Due to the weak concept of subgenera applied for the eastern Asian Batrisodes, the subgeneric system is not used in this paper.
After an examination of the newly collected material, as well as types, photos, and the original descriptions of the described species, we found that all characters used to define Batrisodellus Jeannel to be weak. Since Batrisodellus cannot be clearly separated from Batrisodes, it is placed in synonymy with the latter. In addition, $B a$ sitrodes cornutus Kurbatov is transferred to Batrisodes based on the characters extracted from its original description and figures, and a photo of an identified male.

\section{Material and methods}

The type material of the new species is housed in the Insect Collection of Shanghai Normal University, Shanghai, China (SNUC).

The collecting data of the material are quoted verbatim. A slash is used to separate different labels. Authors' 
supplementary notes are included in square brackets. Each type specimen bears the following label: 'HOLOTYPE [red] (or PARATYPE [yellow]), ô (or + ), $B a$ trisodes + specific name sp. n., det. Yin \& Shen, 2015, SNUC'. Morphological terminology follows Chandler (2001), except our use of 'ventrite' instead of 'sternite' when describing meso- and metathoracic structures.

The following abbreviations are applied: AL_-length of the abdomen along the midline; AW - maximum width of the abdomen; EL-length of the elytra along the sutural line; EW-maximum width of the elytra; HLlength of the head from the anterior clypeal margin to the occipital constriction; HW-width of the head across eyes; PL-length of the pronotum along the midline; PW - maximum width of the pronotum. Length of the body is a combination of $\mathrm{HL}+\mathrm{PL}+\mathrm{EL}+\mathrm{AL}$.

\section{Taxonomy}

\section{Description of new species}

\section{Batrisodes angustelytratus Yin, Shen \& Li, sp. n.}

http://zoobank.org/93776461-DB0B-42F9-B90E-A3C3827E0D2A Figs $1 \mathrm{~A}, 2$

Type material $(3 \widehat{\jmath})$. Holotype: China: $\widehat{\partial}$, labeled 'China: S. Zhejiang, Longquan [龙泉], Fengyang Shan [凤阳山], creek valley nr. hotel, 2754'42”N, $119^{\circ} 11$ '52' $\mathrm{E}$, ant nest under rock, $1175 \mathrm{~m}, 28.1 \mathrm{v} .2014$, X.-B. Song' (SNUC). Paratypes: China: $2 \hat{\jmath} \widehat{\jmath}$, same label data as holotype (SNUC).

Description. Male (Fig. 1A). Body reddish brown, BL 2.12-2.18 mm. Head about as long as wide, HL 0.48$0.49 \mathrm{~mm}$, HW 0.47-0.49 mm; with large vertexal foveae; frons flat, lacking modification, concave between moderately raised antennal tubercles; clypeus coarsely punctate, with round anterior margin; lateral vertexal carinae faintly present from frons to anterior margins of vertexal foveae, median vertexal carina distinct, extending from level of posterior margins of vertexal foveae to base; each eye composed of about 45 facets, lacking ocular canthi; postgenal area with many long erect setae visible in dorsal view. Antennal club (Fig. 2A) formed by apical three antennomeres, IX and X strongly transverse, unmodified, XI large, with distinct, apically-truncate basal denticle. Pronotum about as long as wide, PL 0.48-0.47 mm, PW $0.47-0.46 \mathrm{~mm}$; disc slightly convex; median and lateral longitudinal sulci distinct; lacking median antebasal fovea; with small antebasal tubercles. Elytra much wider than long, EL 0.60-0.63 mm, EW 0.74-0.76 mm; base distinctly constricted; each elytron with three large nude basal foveae; lacking discal striae; marginal striae complete. Mesofemora (Fig. 2B) with thin but distinct ventral spine near middle, mesotibiae (Fig. 2C) with triangular preapical spur; metatibiae (Fig. 2D) with long apical tuft of setae. AL $0.56-0.59 \mathrm{~mm}$, AW 0.79-0.81 mm; abdominal tergite IV (first visible tergite) with strongly oblique marginal carinae; discal carinae short. Length of aedeagus (Fig. 2E-G) $0.44 \mathrm{~mm}$, median lobe broadened in dorso-ventral view, split at apex.

Female. Unknown.

Differential diagnosis. The new species is most similar to Batrisodes fengtingae (Yin \& Nomura) [previously placed in Batrisodellus, transferred to Batrisodes due to the synonymy of these two genera, see below] by sharing similar modification on antennomeres XI and spines on the legs, and an asymmetric aedeagus. Batrisodes angustelytratus can be readily separated from $B$. fengtingae and all other congeners by the strongly constricted elytral base, as well as the unique form of aedeagus.

Biology. Adults were collected from a colony of a Pachycondyla ant nesting under a rock.

Distribution. Eastern China: Zhejiang.

Etymology. The species epithet refers to the strongly constricted base of the elytra.

\section{Batrisodes bamian Yin, Shen \& Li, sp. n.}

http://zoobank.org/6900B5E9-19A3-4467-9C0D-957A56275962 Figs 1B, 3

Type material (5 $\hat{\partial} \hat{\partial}, 1$ + ). Holotype: China: $\hat{\partial}$, labeled 'China: Hunan, Guidong Co. [桂东县], Bamian

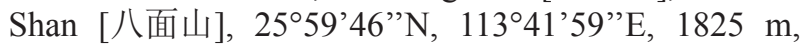
colony of Pseudolasius sp. nesting under moss on rock, 04.vi.2014, Peng \& Shen' (SNUC). Paratypes: China: 4

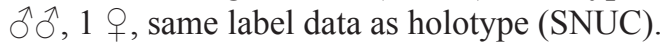

Description. Male (Fig. 1B). Body reddish brown, BL 2.92-2.93 mm. Head about as long as wide, HL 0.55-0.57 $\mathrm{mm}$, HW $0.54-0.55 \mathrm{~mm}$; with small vertexal foveae; frons lacking modification, slightly concave between moderately raised antennal tubercles; clypeus medially impunctate, with round anterior margin; lateral vertexal carinae present from level of midpoints of eyes to posterolateral margins of head, median vertexal carina short; each eye composed of about 60 facets, lacking ocular canthi; postgenal area with numerous long erect setae visible in dorsal view. Antennae lacking distinct club (Fig. 3A-B), IX strongly protruding at lateral margins, $\mathrm{X}$ unmodified, XI large, with distinct basal denticle. Pronotum slightly longer than wide, PL $0.63-0.66 \mathrm{~mm}$, PW $0.55-0.57 \mathrm{~mm}$; disc slightly convex; median longitudinal sulcus thin and shallow, lateral sulci more distinct; lacking median antebasal fovea; with indistinct antebasal tubercles. Elytra wider than long, EL 0.88-0.91 mm, EW 1.02-1.03 mm; each elytron with three nude basal foveae; with short discal striae; marginal striae present in posterior half of flank. Mesofemora (Fig. 3C) with small, blunt ventral spine near middle, mesotibiae (Fig. 3D) with small ventral denticle and apical spur; metatibiae lacking long apical tuft of setae. AL 0.79-0.86 $\mathrm{mm}$, AW 0.93-0.95 mm; abdominal tergite IV (first visible tergite) with oblique marginal carinae; discal carinae as short, triangular ridges. Length of aedeagus (Fig. 3EG) $0.79 \mathrm{~mm}$, median lobe symmetric, endophallus comprising two sclerites. 

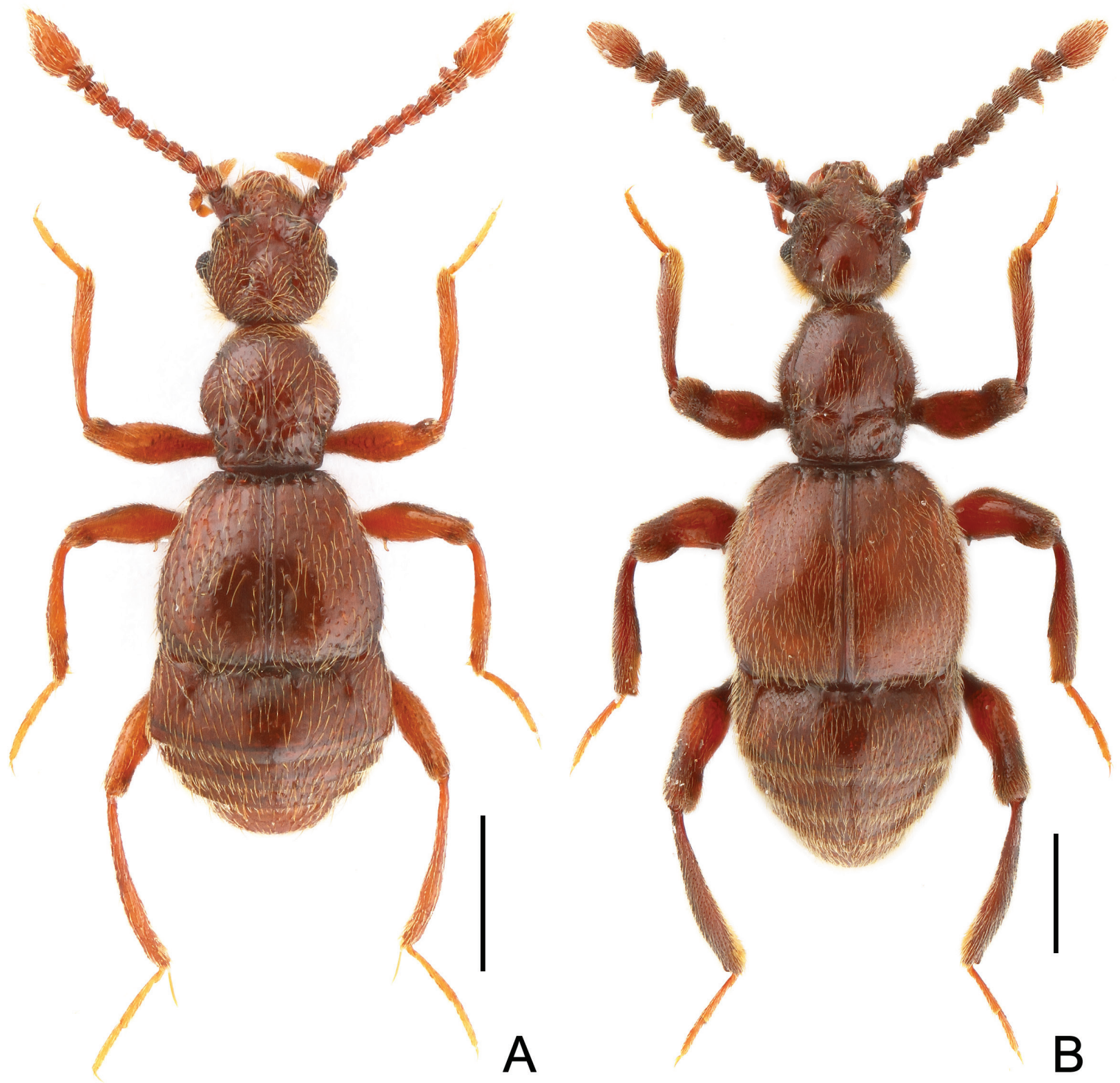

Figure 1. Male habitus of Batrisodes species. A. B. angustelytratus; B. B. bamian. Scales: $0.5 \mathrm{~mm}$.

Female. Much smaller than male, antennae and legs lacking modification and spine; each eye composed of about 40 facets. Tergite VIII (Fig. $3 \mathrm{H}$ ) and sternite VIII (Fig. 3I) transverse. Genital complex (Fig. 3J) well-sclerotized, width $0.37 \mathrm{~mm}$. BL $2.67 \mathrm{~mm}$, HL $0.52 \mathrm{~mm}$, HW $0.53 \mathrm{~mm}$, PL $0.59 \mathrm{~mm}$, PW $0.53 \mathrm{~mm}$, EL $0.78 \mathrm{~mm}$, EW $0.93 \mathrm{~mm}$, AL $0.78 \mathrm{~mm}$, AW $0.86 \mathrm{~mm}$.

Differential diagnosis. The stout habitus and modified antennomere IX, combined with the unique form of the aedeagus readily separates the new species from all other congeners.

Biology. The adults were collected from colonies of a Pseudolasius ant nesting under moss on rocks.

Distribution. Central China: Hunan.

Etymology. The specific epithet refers to the type locality of the new species, Bamian Mountain.
Batrisodes longwangshanus Yin, Shen \& Li, sp. n.

http://zoobank.org/ADCBAF9B-F5F1-43FE-B192-9D5B8F7B3F92 Figs 4A, 5

Type material ( $6 \hat{\jmath} \hat{\sigma}, 3$ + + $)$. Holotype: China: $\hat{\sigma}$, labeled 'China, Zhejiang, Anji County [安吉县], Longwang Shan N. R. [龙王山], Qianmutian-Qianmu Peak [ 千亩田 - 千亩峰], $30^{\circ} 23^{\prime} 47^{\prime}$ N, $19^{\circ} 26^{\prime} 17^{\prime}$ E E, 12501450 m, mixed leaf litter, sifted, 14.v.2013, Chen \& Pan' (SNUC). Paratypes: China: $5 \hat{\jmath} \hat{\jmath}, 3$ + 우, same label data as holotype (SNUC).

Description. Male (Fig. 4A). Body reddish brown, BL 2.23-2.24 mm. Head slightly wider than long, HL 0.46$0.48 \mathrm{~mm}$, HW $0.50-0.51 \mathrm{~mm}$; with big vertexal foveae; frons lacking modification, slightly concave between moderately raised antennal tubercles; clypeus granulate along 


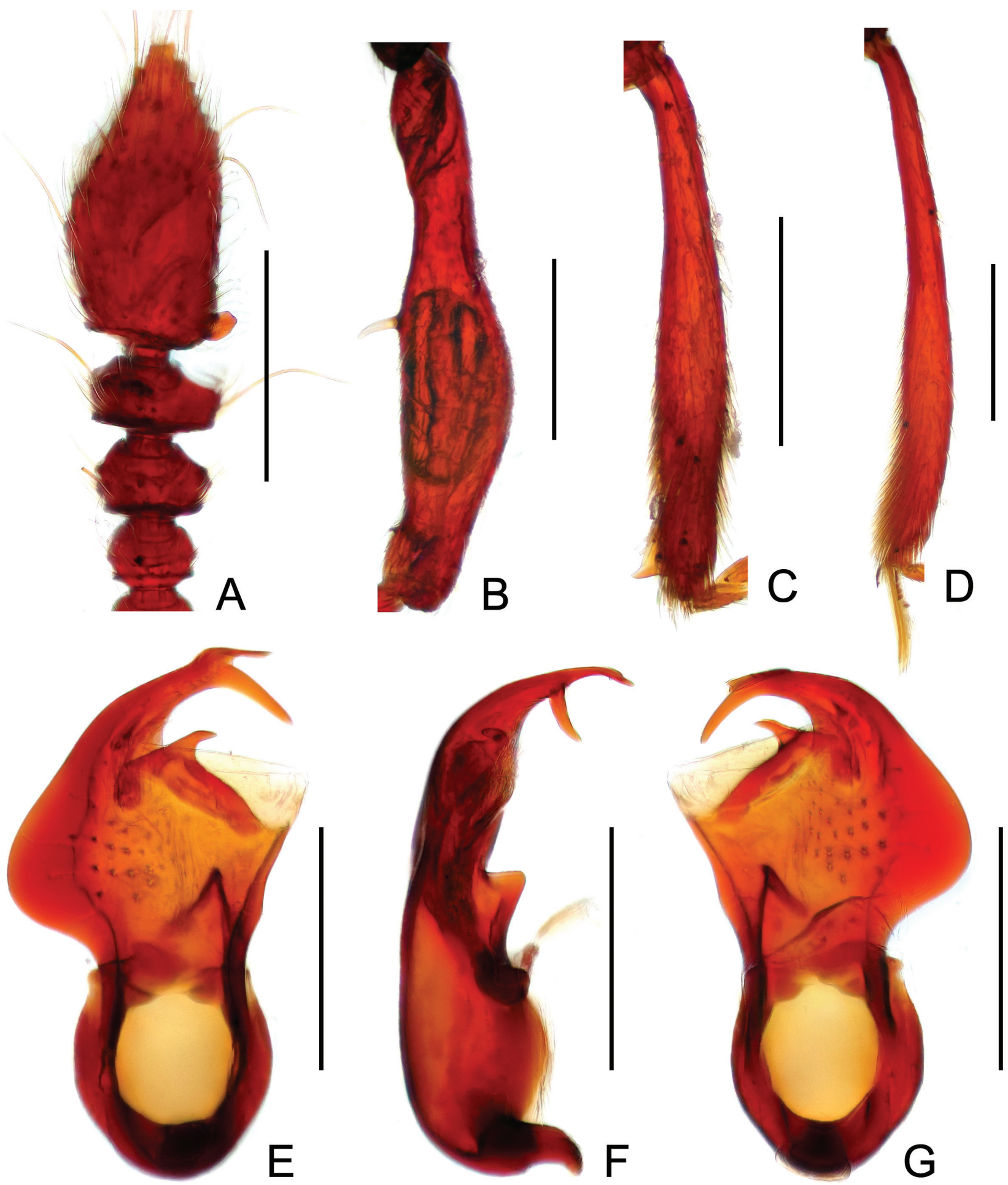

Figure 2. Diagnostic features of Batrisodes angustelytratus, male. A. antennal club; B. mesotrochanter and mesofemur; C. mesotibia; D. metatibia; E. aedeagus, in dorsal view; F. same, in lateral view; G. same, in ventral view. Scales: $0.2 \mathrm{~mm}$.

round anterior margin; lateral vertexal carinae present from level of midpoints of eyes to posterolateral margins of head, lacking median vertexal carina; each eye composed of about 15 facets, with ocular canthi; postgenal area with numerous long erect setae visible in dorsal view. Antennal clubs (Fig. 5A) loosely formed by apical three antennomeres, lacking modification. Pronotum slightly longer than wide, PL 0.47-0.50 mm, PW 0.46-0.47 mm; disc slightly convex; median and lateral longitudinal sulci distinct; lacking median antebasal fovea; with discal and antebasal tubercles along discal ridges, with distinct basolateral tubercles. Elytra wider than long, EL 0.61-0.62 mm, EW $0.73-0.74 \mathrm{~mm}$; each elytron with three large nude basal foveae; with shallow discal striae; marginal striae com- 

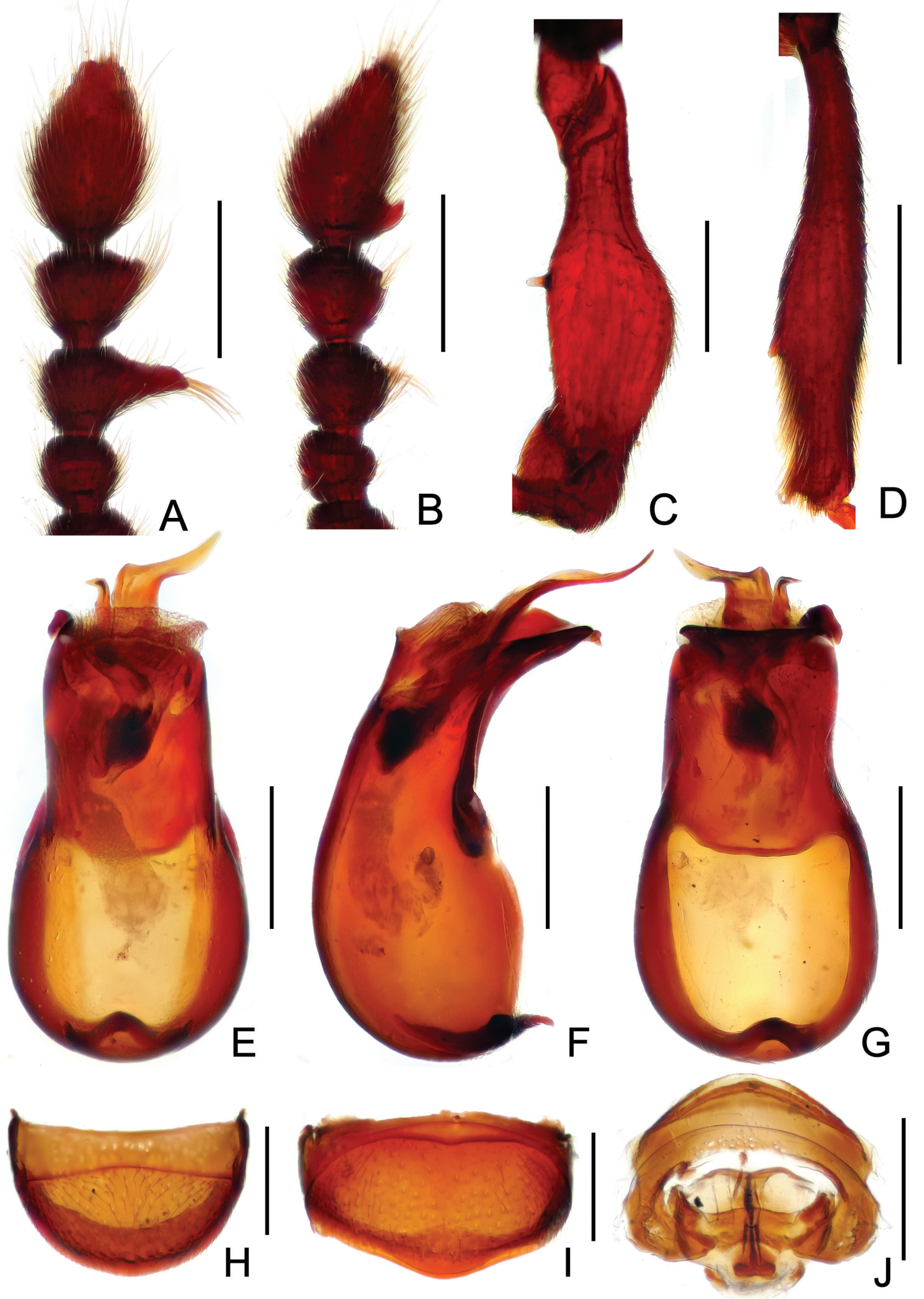

Figure 3. Diagnostic features of Batrisodes bamian (A-G. male; H-J. female). A-B. antennal club; C. mesotrochanter and mesofemur; D. mesotibia; E. aedeagus, in dorsal view; F. same, in lateral view; G. same, in ventral view; H. tergite VIII; I. sternite VIII; J. genital complex. Scales: $0.2 \mathrm{~mm}$. 

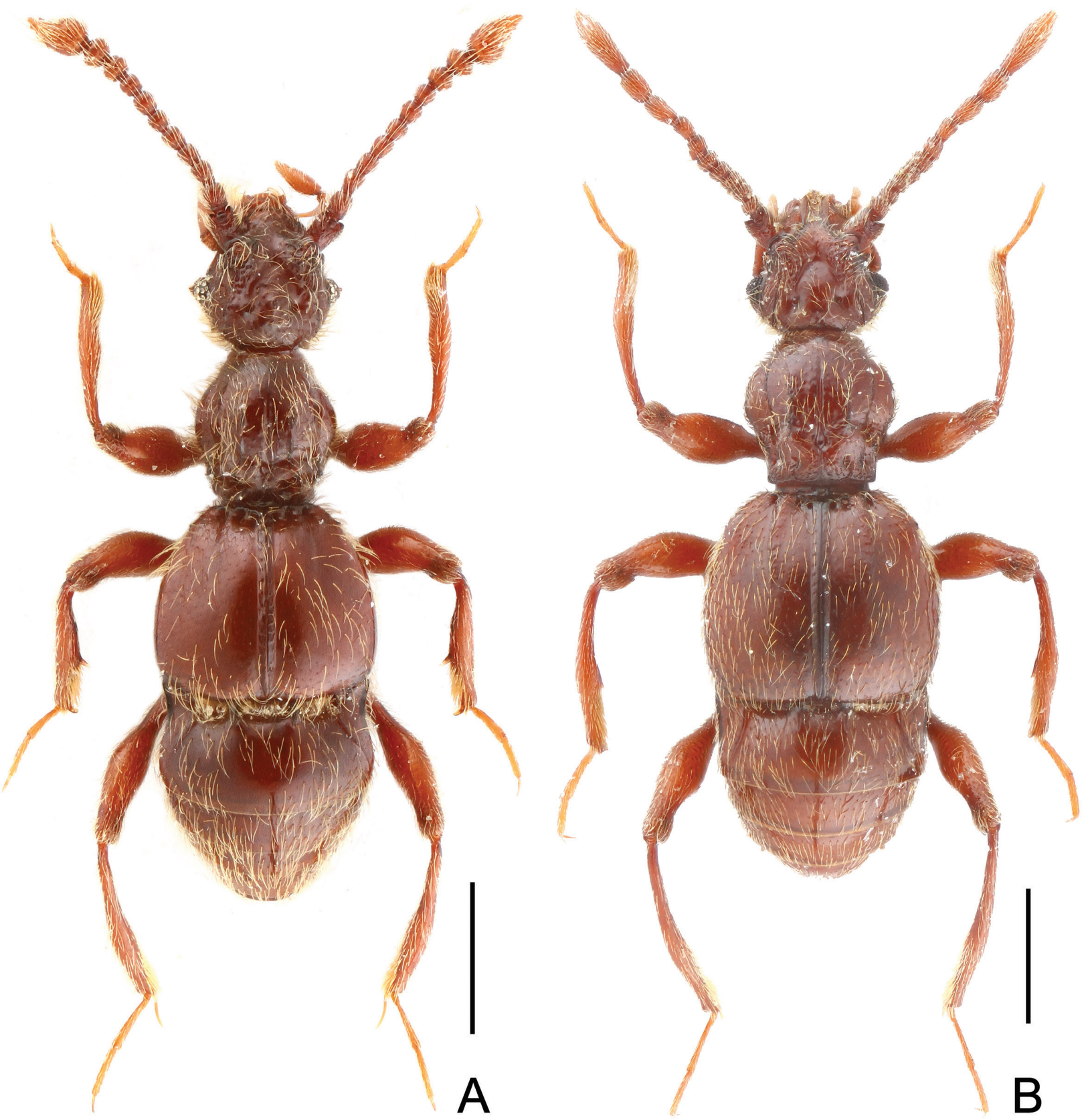

Figure 4. Male habitus of Batrisodes species. A. B. longwangshanus; B. B. songxiaobini. Scales: 0.5 mm.

plete. Protibiae (Fig. 5B) constricted at apical third; mesotrochanters (Fig. 5C) with big ventral spine, mesofemora (Fig. 5C) with small, blunt ventral spine, mesotibiae (Fig. 5D) with sharp ventral denticle and acute apical spur; metatibiae (Fig. 5E) with long apical tuft of setae. AL 0.64-0.69 mm, AW 0.70-0.72 mm; abdominal tergite IV (first visible tergite) with oblique marginal carinae; discal carinae short. Length of aedeagus (Fig. 5F-H) $0.37 \mathrm{~mm}$, median lobe nearly symmetric, with one thin, short and another large, curved styli at right side of apicolateral margin.

Female. Slightly smaller than male, legs lacking modification and spine; each eye composed of about 8 facets. Tergite VIII (Fig. 5I) and sternite VIII (Fig. 5J) transverse. Genital complex (Fig. 5K) weakly sclerotized, width $0.23 \mathrm{~mm}$. BL 2.05-2.14 mm, HL $0.42-0.46 \mathrm{~mm}$, HW 0.48-0.52 mm, PL 0.45-0.46 mm, PW 0.43-0.45 $\mathrm{mm}$, EL $0.57-0.60 \mathrm{~mm}$, EW $0.70-0.72 \mathrm{~mm}$, AL 0.61$0.62 \mathrm{~mm}$, AW $0.65-0.67 \mathrm{~mm}$.

Differential diagnosis. Batrisodes longwangshanus can be separated from all other congeners by a combination of the simple antennal club, the presence of the ocular canthi, the dentate mesotrochanter, mesofemora, and mesotibiae, and the unique form of the aedeagus.

Biology. All adults were collected from leaf litter samples in a mixed forest.

Distribution. Eastern China: Zhejiang.

Etymology. The specific epithet refers to the type locality of the new species, Longwang Mountain. 

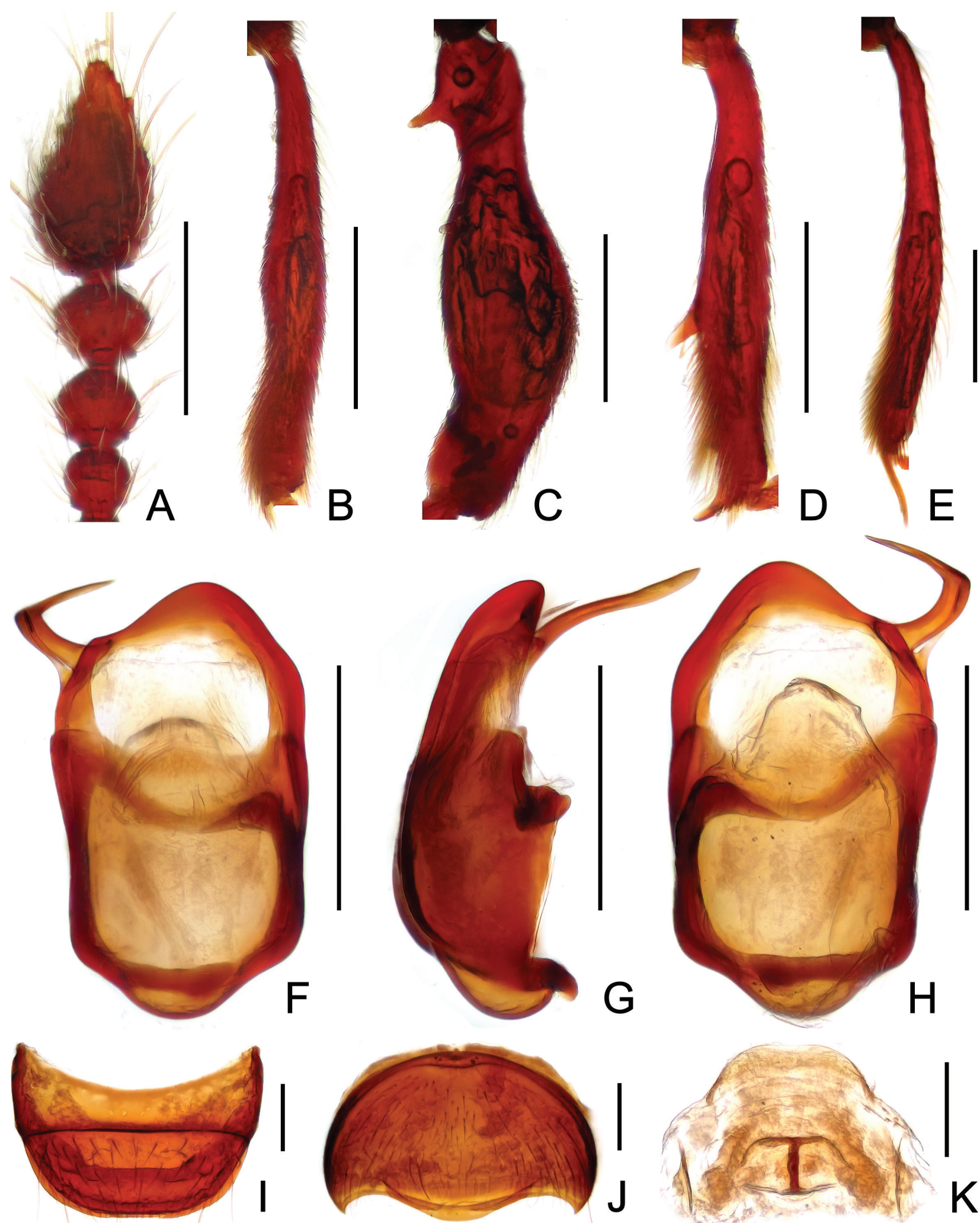

Figure 5. Diagnostic features of Batrisodes longwangshanus (A-H. male; I-K. female). A. antennal club; B. protibia; C. mesotrochanter and mesofemur; D. mesotibia; E. metatibia; F. aedeagus, in dorsal view; G. same, in lateral view; H. same, in ventral view; I. tergite VIII; J. sternite VIII; K. genital complex. Scales: A-H $=0.2 \mathrm{~mm}$; $\mathrm{I}-\mathrm{K}=0.1 \mathrm{~mm}$. 

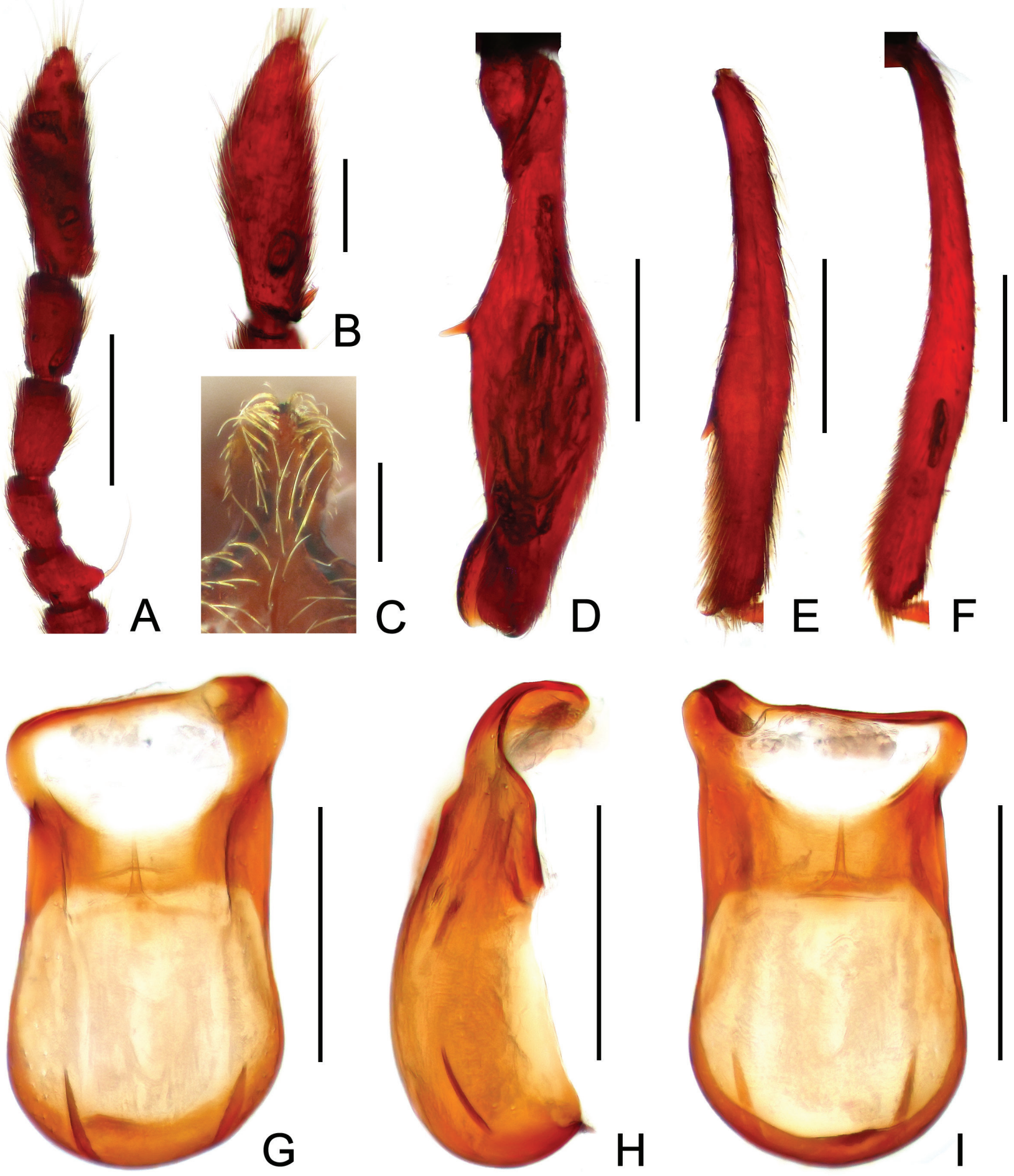

Figure 6. Diagnostic features of Batrisodes songxiaobini, male. A. antennomeres VII-XI; B. antennomere XI, enlarged; C. median projection of frons; D. mesotrochanter and mesofemur; E. mesotibia; F. metatibia; G. aedeagus, in dorsal view; H. same, in lateral view; I. same, in ventral view. Scales: A, D-I $=0.2 \mathrm{~mm}$; B, C $=0.1 \mathrm{~mm}$.

\section{Batrisodes songxiaobini Yin, Shen \& Li, sp. n.}

http://zoobank.org/832A74D6-8C31-4BC7-A927-AF864F5ACFAF Figs 4B, 6

Type material $(6 \hat{\jmath})$. Holotype: China: $\hat{\jmath}$, labeled 'China: Yunnan, Tengchong Co. [腾冲县], Mingguang Town [明光乡], Zizhi Vill. [自治村], Donghe [东河],
2542'55'N, 98³4'52'”E, 2100 m, 01.v.2014, X.-B. Song, [from a nest of Formica sp.]' (SNUC). Paratypes: China: $5 \hat{\jmath}$, same label data as holotype (SNUC).

Description. Male (Fig. 4B). Body reddish brown, BL 2.54-2.60 mm. Head slightly longer than wide, HL $0.52-$ $0.55 \mathrm{~mm}$, HW $0.53-0.54 \mathrm{~mm}$; with small vertexal foveae; frons strongly protruding anteriorly at middle (Fig. 6C); 
clypeus lacking punctation, with round anterior margin; lateral vertexal carinae present from level of anterior margins of eyes to posterolateral margins of head, with short median vertexal carina; each eye composed of about 55 facets, lacking ocular canthi; postgenal area with many long erect setae visible in dorsal view. Antennal clubs (Fig. 6A) formed by apical three antennomeres; antennomeres VII expanded at base, with one long, thick seta at apex of expansion, antennomeres VIII-XI each elongate, XI (Fig. 6B) with small denticle at base. Pronotum slightly longer than wide, PL $0.57-0.59 \mathrm{~mm}$, PW $0.51-0.57 \mathrm{~mm}$; disc slightly convex; with distinct median and lateral longitudinal sulci; lacking median antebasal fovea; with small basolateral tubercles. Elytra wider than long, EL 0.75-0.77 mm, EW 0.88-0.90 $\mathrm{mm}$; each elytron with three large nude basal foveae; with shallow discal striae; marginal striae complete. Mesofemora (Fig. 6D) with small, sharp ventral spine, mesotibiae (Fig. 6E) with small ventral denticle and small, acute apical spur; metatibiae (Fig. 6F) with short apical tuft of setae. AL 0.68-0.71 mm, AW 0.77-0.78 mm; abdominal tergite IV (first visible tergite) with oblique marginal carinae; discal carinae short. Length of aedeagus (Fig. 6G-I) $0.40 \mathrm{~mm}$, median lobe nearly symmetric, with one spine-like sclerite at middle of anterior margin of foramen.

Female. Unknown.

Differential diagnosis. The protruding anterior margin of the frons is shared in a number of Asian species, e.g. Batrisodes cornutus (Kurbatov) (transferred from the genus Basitrodes, see below), and Batrisodes acutifrons Jeannel. But the characteristic forms of the antennomeres VII-XI and protruding frons in the male, as well as the aedeagal structure readily separate this new species from all other congeners.

Biology. Adults were collected from a colony of a Formica ant nesting under a rock.

Distribution. Southwestern China: Yunnan.

Etymology. The species epithet recognizes the collecting efforts of Xiao-Bin Song, who collected the type series and many other interesting pselaphines.

\section{New synonymy and new combinations}

René Jeannel (Jeannel 1958) in his treatment of Japanese Pselaphinae created a number of new genera placed near Batrisodes, e.g. Basitrodes Jeannel, Petaloscapus Jeannel, Batrisodellus, Kigatrodes Jeannel, and Speobatrisodes Jeannel. All of these taxa were defined based on weak characters which are either variable in a genus, or merely male sexual features, e.g. the form of the aedeagus, and the modification of male antennomeres. In our opinion their diagnoses and relationships to Batrisodes must be revised in the future.

The genus Batrisodellus (type species: Batrisodes nipponensis Raffray), comprising nine species from Japan and one species from China (Shibata et al. 2013; Yin, Nomura and Zhao 2011), was originally characterized by the presence of a basal denticle on male antennomeres $\mathrm{XI}$, the dentate male mesofemora and mesotibiae, and the symmetric, scaphoid aedeagus (Jeannel 1958). In fact, the aedeagus in the Chinese species presents an asymmetric form, while the other characters frequently occur in many Batrisodes species. Since none of these characters can be used to effectively separate Batrisodellus from Batrisodes, the two genera are synonymized here, with Batrisodellus being the junior synonym of Batrisodes, syn. n. As a consequence, all ten species currently placed in Batrisodellus are transferred to Batrisodes: Batrisodes acuminatus (Sharp) comb. rev., Batrisodes cerberus (Tanabe \& Nakane) comb. n., Batrisodes coprea (Tanabe \& Nakane) comb. n., Batrisodes cristatus (Jeannel) comb. n., Batrisodes fengtingae (Yin \& Nomura) comb. n., Batrisodes laticollis (Jeannel) comb. n., Batrisodes longulus (Jeannel) comb. n., Batrisodes nipponensis Raffray comb. rev., Batrisodes palpalis (Sharp) comb. n., and Batrisodes punctipennis (Sharp) comb. $\mathbf{n}$.

According to the original description (Kurbatov 1984), the Russian Far East species Basitrodes cornutus Kurbatov lacks the unique aedeagal form of Basitrodes, but shares many characters typical of Batrisodes. After an examination of a high-resolution photo of an identified male [collecting data: Kunashir Is., cordon Alekhinskij, rotten Abies, 31.VII.2011, Kurbatov leg.], this species is here moved to Batrisodes comb. n.

\section{Nomenclatural change}

The name Batrisodes (Excavodes) simplex Yin \& Li, 2013 is a primary junior homonym of Batrisodes simplex (LeConte, 1878), the latter is a junior synonym of $\mathrm{Ba}$ trisodes (Pubimodes) striatus striatus (LeConte, 1849) (Chandler 1997). Hence we propose a new replacement name: Batrisodes (Excavodes) pengzhongi.

Etymology. The new name is dedicated to Zhong Peng, who collected most specimens of the type series of this species.

\section{Acknowledgements}

We thank Donald S. Chandler (Durham, U.S.A.) for providing discussion before submission of the manuscript. Serguei Kurbatov (Moscow, Russia) kindly provided a picture of an identified male of Batrisodes cornutus. Peter Hlaváč (Praha, Czech Republic) and Alexey Solodovnikov (Copenhagen, Denmark) critically read a previous draft and gave helpful comments. The present study was supported by the National Science Foundation of China (No. 31172134) and Science and Technology Commission of Shanghai Municipality (No. 15YF1408700). The open access fee was covered by $\mathrm{Mu}-$ seum für Naturkunde Berlin.

\section{References}

Besuchet C (1981) Contribution à l'étude des Batrisodes paléarctiques (Coleoptera: Pselaphidae). Revue Suisse de Zoologie 88: 275-296. 
Chandler DS (1997) A Catalog of the Coleoptera of America North of Mexico. Family: Pselaphidae. United States Department of Agriculture, Agriculture Handbook, Number 529-31: ix + 118 pp.

Chandler DS (2001) Biology, morphology, and systematics of the antlike litter beetles of Australia (Coleoptera: Staphylinidae: Pselaphinae). Memoirs on Entomology International 15: 1-560.

Jeannel R (1958) Révision des psélaphides du Japon. Mémoires du Muséum National d'Histoire Naturelle, (N.S., Série A, Zoologie) 18: 1-138.

Kurbatov S (1984) Two new species of pselaphid beetles (Coleoptera) from the Kunashir Island. Zoologicheskii Zhurnal. 64: 145-147. [in Russian with English abstract]

Nomura S (2007) Two new species of the genus Batrisodes (Coleoptera, Staphylinidae, Pselaphinae) from Taiwan. Elytra 35: 76-84.
Shibata Y, Maruyama M, Hoshina H, Kishimoto T, Naomi S, Nomura S, Puthz V, Shimada T, Watanabe Y, Yamamoto S (2013) Catalogue of Japanese Staphylinidae (Insecta: Coleoptera). Bulletin of the Kyushu University Museum 11: 69-218.

Yin ZW, Li LZ (2013) Batrisodes (Excavodes) simplex sp. n. (Coleoptera: Staphylinidae: Pselaphinae): a second species of the genus from continental China. Deutsche Entomologische Zeitschrift 60: 261-266.

Yin ZW, Nomura S, Zhao MJ (2011) Taxonomic study on Batrisodellus Jeannel of China, with discussion on the systematic position of $B a$ trisodellus callissimus Nomura \& Wang, 1991. Spixiana 34: 33-38. 